\title{
A New Tropical Species of Psathyrella (Psathyrellaceae, Agaricales) From the Cúc Phương National Park, Vietnam
}

\section{Enrico Büttner ( $\nabla$ enrico.buettner@tu-dresden.de )}

Department of Bio- and Environmental Sciences, International Institute Zittau, Technische Universität Dresden, Zittau, Germany https://orcid.org/0000-0002-8589-8483

\section{Alexander Karich}

Department of Bio- and Environmental Sciences, International Institute Zittau, Technische Universität

Dresden, Zittau, Germany

\section{Do Huu Nghi}

Experimental Biology Lab., Institute of Natural Products Chemistry, Vietnam Academy of Science and Technology; 18 Hoang Quoc Viet, Cau Giay, Hanoi, Vietnam

\section{Maximilian Lange}

Department of Bio- and Environmental Sciences, International Institute Zittau, Technische Universität Dresden, Zittau, Germany

\section{Christiane Liers}

Department of Bio- and Environmental Sciences, International Institute Zittau, Technische Universität Dresden, Zittau, Germany

\section{Harald Kellner}

Department of Bio- and Environmental Sciences, International Institute Zittau, Technische Universität Dresden, Zittau, Germany

\section{Martin Hofrichter}

Department of Bio- and Environmental Sciences, International Institute Zittau, Technische Universität Dresden, Zittau, Germany

\section{René Ullrich}

Department of Bio- and Environmental Sciences, International Institute Zittau, Technische Universität Dresden, Zittau, Germany

\section{Research}

Keywords: Agaricales, basidiomycota, phylogeny, Psathyrella, taxonomy, Vietnam, wood-rot

Posted Date: August 13th, 2020

DOl: https://doi.org/10.21203/rs.3.rs-57408/v1 
License: (c) (i) This work is licensed under a Creative Commons Attribution 4.0 International License. Read Full License 


\section{Abstract}

Basidiocarps of a hitherto undescribed Psathyrella species were collected during a sampling excursion in North Vietnam. They grew on deciduous deadwood in the Southeastern part of the Cúc Phương National Park (Vietnamese: Vườn quốc gia Cúc Phương), Ninh Bình Province. Herein, we describe Psathyrella euryspora sp. nov. characterized by broadly ellipsoid to broadly ovoid basidiospores $(5.5-7.0 \times 4-5(-6))$ $\mu \mathrm{m}$ without visible germ pore, utriform to ventricose-clavate cheilocystidia, heteromorphic caulocystidia and the absence of pleurocystidia and pileocystidia. Based on an isolated pure culture, the genome was sequenced and a full ribosomal RNA gene cistron including 18S, internal transcribed spacer 1 (ITS), 5.8S, ITS2 and 28S rRNA annotated. Phylogenetic analysis of $P$. euryspora revealed its close affiliation to the Psathyrella sect. Candolleanae species clade.

\section{Introduction}

The dark spored agaric genus Psathyrella (Fr.) Quél. is ubiquitously distributed across the world (Hoashi 2008; Singer 1978; Van Waveren 1985). Thus, Psathyrella species can be found in arctic or alpine regions but in the subtropics and tropics as well (Pegler 1983, 1977; Smith 1972). Although, over 900 species have been described so far (http://www.mycobank.org), the number of which is steadily increasing (Melzer et al. 2018; Sicoli et al. 2019; Yan and Bau 2018).

Species of the genus are usually following saprotrophic lifestyles and thus, grow on deadwood, plant debris, dung, leaf-litter or humus-rich soil. The genus' name refers to the fragile or brittle constitution of fruiting bodies, which all Psathyrella species have in common (diminutive of Psathyra, from Old Greek uaӨupos $=$ friable, cumbling).

Recent molecular studies have indicated closer relation of the genus to other psathyrelloid genera, such as Coprinellus P. Karst. and Coprinopsis P. Karst. (Matheny et al. 2006; Nagy et al. 2009; Örstadius et al. 2015; Redhead et al. 2001). In consequence, these genera were included into the family of Psathyrellaceae, which, according to Örstadius et al. (2015), now includes Coprinopsis, Parasola Redhead, Vilgalys \& Hopple, Lacrymaria Pat., Typhrasa (Britzelm.) W.B. Cooke, Psathyrella sensu lato (including the aforementioned genus Coprinellus, and additionally Kauffmania Örstadius \& E. Larss., Typhrasa Örstadius \& E. Larss. and Cystoagaricus Singer) and Psathyrella sensu stricto. Within Northern species of the genus Psathyrella, 17 clades have been identified (Örstadius et al. 2015), of which / candolleana is well supported and the closest relative to Coprinellus. A commonly distributed morphologic feature within / candolleana is the absence of pleurocystidia.

A Psathyrella basidiocarp resembling the recently described species $P$. aberdarensis A. Melzer, Kimani \& R. Ullrich was collected during a sampling excursion with focus on macrofungi in the Cúc Phương National Park (Vietnamese: Vườn quốc gia Cúc Phương, Ninh Bình Province, North Vietnam) in November 2018. This specimen, from which a strain was isolated, turned out to microscopically deviate from all known Psathyrella spp. and therefore, shall be described herein. In addition, the strain was sequenced 
and its full genome sequence providing relevant data for further phylogenetic and biotechnological analyses deposited at NCBI (National Centre for Biotechnology Information) Bioproject PRJNA647680.

Although, Vietnam is without doubt a hotspot of biodiversity, only little information is currently available on the funga of this country (de Queiroz et al. 2013). For example, the Global Biodiversity Information Facility (https://www.gbif.org) does not list any Vietnamese fungal herbarium or culture collection entry. On the other hand, the enormous diversity of large uncharted regions in Vietnam (Collen et al. 2014) will surely lead to the discovery of more fungal species, as it has recently been reported in a survey on comparable Chinese regions (Yan and Bau 2018).

\section{Materials And Methods}

A twig bearing two fresh basidiomata was collected in Cúc Phương National Park and transferred to Zittau (Germany) for further cultivation and examination. The in situ collected twig was placed under saturation vapor at $23^{\circ} \mathrm{C}$ in an incubation chamber. After about five weeks three basidiocarps grew on the twig consecutively within a month. An axenic pure fungal strain was isolated from this material using $2 \%$ malt-agar plates with antibiotic additions $(50 \mu \mathrm{g} / \mathrm{ml}$ streptomycin, penicillin, chloramphenicol, benomyl and $40 \mu \mathrm{g} / \mathrm{ml}$ nystatin). The strain was deposited at the Vietnam Type Culture Collection (VTCC, Hanoi, Vietnam) under number VTCC 930004.

\section{Morphology}

Dried specimen voucher are deposited at the Herbarium Senckenbergianum Görlitz, Germany (GLMF126263). All macroscopic characteristics were recorded based on fresh material. Photographs of the cultivated basidiomata were taken and color codes are based on the RGB color model (Poynton 2003). Microscopic characteristics were analyzed based on hand sections of fresh and revived material (Zeiss, Axio Scope A1, Oberkochen, Germany; Canon EOS 60 D, Tokyo, Japan). The spore size was measured in water using spores from a spore print at the stipe apex. Color of spores was assessed in water, ammonia solution (10\%) and potassium hydroxide solution ( $5 \% \mathrm{w} / \mathrm{v} \mathrm{KOH})$. Cystidia and other microscopic structures were studied in $5 \% \mathrm{KOH}$.

\section{DNA Extraction, Genome Sequencing and ribosomal RNA gene retrieval}

Biomass of a culture plate of Psathyrella euryspora was scraped off to extract genomic DNA by a standard acetyltrimethylammonium bromide (CTAB)-based method. Genomic DNA was sonographically sheared with a S2 ultrasonicator (Covaris, Woburn, MA, USA) to subsequently construct a 400 bp library using the lon Plus Fragment Library Kit (Thermo Fisher, Darmstadt, Germany). The library was sequenced on an lon GeneStudio ${ }^{\text {TM }}$ S 5 System using the lon 530 Chip Kit. The resulting 11.3 million reads were filtered to include lengths between 300 and $625 \mathrm{bp}$ and were assembled using MIRA 4.0 (minimum reads per contig $=100$, mode $=$ accurate; Chevreux et al., 1999). Overlapping contigs were joined and duplicate contigs were filtered using, in a second step, the Geneious assembler R11.4.1 (parameter: highest 
sensitivity/slow; Kearse et al., 2012). For complete annotation of the full ribosomal RNA gene cistron including 18S (SSU), internal transcribed spacer 1 (ITS), 5.8S, ITS2 and 28S (LSU) rRNA gene regions and spacer, the contig was manually identified comparing references obtained from NCBI nr-Database to the full assembly including all contigs. The full ribosomal cistron including SSU, LSU and 5.8S rRNA gene regions are available at GenBank under accession number MT651560. The lonTorrent raw reads have been deposited at the Sequence Read Archive (NCBI) under accession number SRR12301154.

\section{Alignment and Phylogenetic Analysis}

In a first step, the identified $P$. euryspora ITS and 28S rRNA (D1-D3) gene regions were used to find similar sequences of the genus Psathyrella (sensu stricto, outgroup generated) and specifically of the $P$. candolleana subclade in NCBI GenBank using a blastn search (E-value $\left.1 \mathrm{e}^{-1}\right)$. Phylogeny of the taxonomic classification of the clades is given in supplement S1. Additional information on $\beta$-tubulin and the translation elongation factor (tef) 1 a can be accessed in supplement S2 (i.e. gene and protein). Furthermore, a set of sequence data including ITS region and the 28S rRNA gene region (as far as available) of the $P$. candolleana clade was composed and is listed in Table 1. Alignments were calculated using MUSCLE 3.8.425 (Edgar 2004) with default settings integrated in Geneious R11. Phylogenies were constructed using MEGA 10.0.5 (Kumar et al. 2018). For both sets, a maximum likelihood approach after a model selection was used (Guindon and Gascuel 2003). The substitution model with the lowest Bayesian Information Criterion (BIC) score was chosen (K2+G+I, Kimura, 1980). Branch support was estimated by using a bootstrap approach using 1,000 replicates. Furthermore, a Bayesian approach using MrBayes 3.2.6 (Huelsenbeck and Ronquist 2001; Ronquist et al. 2012) integrated in Geneious was used (substitution model: general time reversible (GTR) with gamma distributed rate variation among sites (+ G); chain length: 1,100,000; burn-in: 100,000; chains: 4; sample frequency: 200). 
Table 1

Fungal species (27 records) used for phylogenetic analyses of the clade of / candolleana including GenBank accession numbers of the ITS regions.

\begin{tabular}{|llll|}
\hline Organism & $\begin{array}{l}\text { GenBank accession } \\
\text { No. }\end{array}$ & Organism & $\begin{array}{l}\text { GenBank accession } \\
\text { No. }\end{array}$ \\
\hline Coprinellus micaceus & HM240519 & P. luteopallida & MG734736 \\
\hline C. silvaticus & KC992943 & P. secotioides & KR003281 \\
\hline C. xanthothrix & HF543673 & P. singeri & MG734718 \\
\hline $\begin{array}{l}\text { Psathyrella } \\
\text { aberdarensis }\end{array}$ & MK421517 & P. subsingeri & MG734714 \\
\hline P. badhyzensis & KC992883 & P. subsingeri & MG734742 \\
\hline P. cacao & KX017210 & P. subsingeri & NR160505 \\
\hline P. cacao & NR148106 & P. & KJ138423 \\
\hline P. candolleana & DQ389720 & P. & KJ138tuberculosa \\
\hline P. efflorescens & KC992941 & Pulcatotuberculosa & \\
\hline P. euryospora & MT651560 & P. tuberculata & KC992886 \\
\hline P. halophila & MG825900 & P. tuberculata & KC992934 \\
\hline P. lacuum & KC992887 & P. typhae & JX077004 \\
\hline P. leucotephra & KC992885 & P. typhae & DQ389721 \\
\hline P. luteopallida & KC992884 & & \\
\hline
\end{tabular}

\section{Results}

\section{Phylogenetical results}

The draft genome of $P$. euryspora is represented by 1,966 assembled contigs, a size of $70.0 \mathrm{Mb}$ and a G + C content of $50.0 \%$. Altogether 16,680 genes were predicted using AUGUSTUS (Stanke et al. 2004). A query of the ITS region by known representatives of the genus Psathyrella provided a clear picture. Regions of ITS1 (272 bp), 5.8S rRNA (157 bp) and ITS2 (237 bp) were strictly annotated. Further regions (SSU, LSU) for phylogenetic studies were adapted from known sequences. In comparison, ITS/28S rRNA gene sequence showed the highest similarity (98.7\%) to the recently described species $P$. aberdarensis A. Melzer, Kimani \& R. Ullrich from Kenya. Furthermore, sequences of $\beta$-tubulin and tef1a protein of both species were to $99.77 \%$ and $98.91 \%$, respectively, identical (sequences included in supplement file S2). The ML phylogeny using ITS/28S rRNA genes placed the new species in a well-supported clade within / candolleana, more distinctly in a subclade together with P. sulcatotuberculosa (J. Favre) Einhell. and $P$. 
aberdarensis. A detailed analysis of the / candolleana clade was performed including ITS and 28S rRNA regions. (Fig. 1). As the outcome, $P$. sulcatotuberculosa and $P$. aberdarensis, the new Vietnamese specimen and the sequence of a specimen that is regarded as $P$. singeri form a well-supported subclade ( $n=1,000$ bootstrap), namely / sulcatotuberculosa.

\section{Taxonomy}

Psathyrella euryspora A. Karich, E. Büttner \& R. Ullrich sp. nov. (Figs. 2-4)

MycoBank: MB 836196

GenBank: MT651560

\section{Etymology}

Name refers to rather broad spores - eurýs - ancient greek $\varepsilon \llbracket \rho u ́ \varsigma$ = broad, wide.

\section{Latin diagnosis}

Pileus usque ad $12 \mathrm{~mm}$ latus, conicus vel hemisphaericus, deinde applanatus, cremeus vel pallide brunneus, umide usque ad 2/3 pellucide striatus. Velum album, floccosum, usque ad medium pilei. Lamellae c. 30, mediis intervallis distantes, adnexe vel adnatae, primum pallide brunnea, acie albae, non deliquescens. Stipes usque ad $20 \times 1 \mathrm{~mm}$, cylindraceus, albus vel cremeus, apice pruinosus, basi tomentosus. Basidia 12-19.5 ×6.5-9 $\mu \mathrm{m}$, clavata, 4-sporigera. Sporae $(5-) 5.5-7.0(-7.5) \times 4-5(-6) \mu \mathrm{m}$, lato-ellipsoideae vel ovoideae, pallide brunneae, poro germinativo nullo. Cheilocystidia 18-25 ×9$11.5 \mu \mathrm{m}$, utriformia vel clavata. Pleurocystidia nulla. Caulocystidia lageniformia, subcylindrica vel utriformia, cellulis sphaeropedunculatis et clavatis immixtis. Cellulae veli cylindraceae et subhyalina vel pallide brunnea. Fibulae praesentes. Basidiomata solitaria ad lignum emortuum.

\section{English diagnosis}

Pileus 6-12 mm, concial to campanulate. Stipe slender. Basidiospores $(5-) 5.5-7.0(-7.5) \times 4-5(-6) \mu \mathrm{m}$ broadly ellipsoid to broadly ovoid, germ pore not visible. Cheilocystidia $18-25 \times 9-11.5 \mu \mathrm{m}$, utriform to ventricose-clavate. Caulocystidia 18-43 $\times 8-12 \mu \mathrm{m}$, heteromorphic, subfusiform to lageniform. Pleurocystidia and pileocystidia absent. Veilar hyphae cylindrical, subhyaline to pale brown, slightly encrusting.

\section{Holotype}

Cultivated in Zittau, Germany, December 13, 2018; the holotype was deposited as basidiomata at the Herbarium Senckenbergianum Görlitz, Germany (GLM-F126263), and a pure culture was deposited at the Vietnam Type Culture Collection Hanoi under VTCC 930004. Origin: Vietnam, Ninh Bình Province: Cúc Phương National Park, $20^{\circ} 17.61^{\prime} \mathrm{N} 105^{\circ} 40.0517 ' E$; approx. $267 \mathrm{~m}$ asl; November 21st 2018; leg. Enrico Büttner. 


\section{Description}

Pileus 6-12 mm wide, at first conical to campanulate, later semiglobate to broad conical to flattening, old with a wavy margin, at first whitish-cream (R:190 G:190 B:140) later becoming more brownish (R:180 G:180 B:120), finally darker brown with olive tinge (R:100 G:90 B:40) center remaining brighter, translucently striate up to $2 / 3 \mathrm{rd}$ when fresh, hygrophaneous, universal veil as loosely adhering but quite persistent floccules on the cap (Fig. 2). Lamellae medium spaced to crowded, $L=28-30$, interspersed with 1-3 lamellulae, adnexed to adnate, dark-cream to brownish, finally becoming brown at age, lamellar edge white, pruinose (lens). Stipe up 15-20 $\mathrm{mm} \times 1 \mathrm{~mm}$, cylindrical, white in the upper part, downwards somewhat brownish-creamy, tip pruinose from caulocystidia, base white tomentose.

Basidiospores (5-)5.5-7.0(-7.5) × 4-5(-6) $\mu \mathrm{m}$, average 6.2 × 4.4 $\mu \mathrm{m}, \mathrm{Q}=1.2-1.6(-1.7)$, Qav. $=1.4$, in front view broadly ellipsoid to ovoid, in side view broadly ellipsoid and sometimes adaxially very slightly flattened, apiculus tiny, germ pore not visible; in water and ammonia solution pale brown, in $\mathrm{KOH}$ nearly hyaline (Fig. 3,4); a small portion of spores (approx. 5\%) in the spore print (i.e. at the stem of sporocarps) germinating, with an up to $10 \mu \mathrm{m}$ long hyphae growing of the apical part of the spore. Basidia 12-19.5 $\times$ 6.5-9 $\mu \mathrm{m}$, 4-spored, clavate. Cheilocystidia 18-25 $\times 9-11.5 \mu \mathrm{m}$, broadly utriform to clavate, very rare and hard to distinguish from sphaeropedunculate to clavate-pyriform cells (paracystidia), 15.8-23 11 $16.6 \mu \mathrm{m}$; all marginal cells thin-walled and colourless. Pleurocystidia absent. Caulocystidia $18-43 \times 8-$ $12 \mu \mathrm{m}$, heteromorphic, broadly to narrowly utriform, subfusiform, lageniform, at the tip of the stem only, numerous, intermixed with sphaeropedunculate and clavate-pyriform elements, $18.5-33 \times 11-16 \mu \mathrm{m}$. Veil consisting of 20-75 $\times 4-11 \mu \mathrm{m}$, cylindrical, slightly diverticulate, subhyaline to pale brown hyphae, some hyphae finely to distinctly banded incrusted. Pileipellis and epithelium consist of up to $40 \mu \mathrm{m}$ wide, globose to subglobose hyaline to pale brown elements. Clamp connections are present in veil, hymenium and mycelium.

\section{Habit and habitat.}

Solitary on deadwood (fallen twigs) of broad-leaved trees. Humid and near-ground habitat.

\section{Discussion}

Psathyrella euryspora is characterized by its small sporocarps, its flocculose yet relatively persistent veil consisting of rather thin walled and moderately encrusted, cylindric hyphae as well as by its small, broad $(\mathrm{QAV} .<1.5)$ and pale spores without a visible germ pore.

According to DNA-analysis, $P$. euryspora is closely related to $P$. aberdarensis and $P$. sulcatotuberculosa. The latter, seemingly rare species had been listed as a variety of $P$. typhae (Kalchbr.) A. Pearson \& Dennis for a long time and was later placed into the / candolleana clade (Battistin et al. 2014; Matheny et al. 2006). Both species, however, can bear lageniform cheilocystidia and seem to be restricted to humid/wet habitats, which is in contrast to P. euryspora (Battistin et al. 2014; Ludwig 2007). 
Another closely related species is Psathyrella singeri A. H. Sm (Melzer et al. 2018), which was described as a twig-dwelling fungus from Florida (Smith 1972). Smith did not mention any veil and described the lamellae being crowded. The ITS sequence of a specimen collected in China and determined as $P$. singeri was deposited in GenBank (compare Table 1) and differs from sequences of $P$. euryspora. It is unclear, however, whether this specimen is in fact $P$. singeri (Melzer et al. 2018). Nevertheless, all mentioned species have very pale spores and share the same branch / sulcatotuberculosa within the Candolleanae clade (compare Fig. 3). However, P. euryspora differs from other species within / sulcatotuberculosa by having smaller and more rotund spores. Obviously, there are two different veil types within / sulcatotuberculosa. The veil of $P$. aberdarensis consists of two types of cells, i.e. (i) diverticulate, often thick walled and brownish pigmented cells and (ii) globose elements (Melzer et al. 2018). In contrast, the veil elements of $P$. euryspora consist of cylindrical, subhyaline to pale brown and - in some parts - slightly encrusted hyphae, and therefore resemble the veil hyphae of $P$. sulcatotuberculosa (Battistin et al. 2014).

Other species with more or less pale spores, lacking or indistinct germ pore and without pleurocystidia were already discussed in Melzer et al. (2018) but shall be mentioned here again .

Psathyrella acutisquamosa Dennis has abundant veil as pyramidal warts, equally sized $(5-7 \times 4-5 \mu \mathrm{m})$ but reddish spores (Dennis 1961).

Psathyrella aequatoriae Singer is a small species without veil and larger spores $(7-8 \times 4-5 \mu \mathrm{m})$ (Singer 1978).

Psathyrella avilana Dennis grows caespitosely and terrestrially, has only fugacious veil and less broad spores $(6-6.5 \times 3.5-4 \mu \mathrm{m}$; Dennis 1961).

Psathyrella bivelata Contu has a different veil structure and larger, thick-walled spores $(9-9.5 \times 5-5.5 \mu \mathrm{m}$ in av.; Contu 1991; Melzer et al. 2018; Sammut and Melzer 2012; Voto 2011).

Psathyrella efflorescens Berk. \& Broome has also equally sized and pale spores but differs in having smaller cheilocystidia $(12-15 \times 7.5-10 \mu \mathrm{m})$, by its caespitose habit, purplish tints in the pileus and by its ITS-sequence (compare Fig. 1; Pegler 1977).

Psathyrella glaucescens Dennis has olive shades on the cap as well but differs by a larger pileus (1.5$5 \mathrm{~cm}$ ), an only slightly translucently striate margin, fugacious veil made of ventricose elements and by truncate spores with a porus (Dennis 1961; Pegler 1977).

Psathyrella pallidispora Dennis has 8-11 $\times 4-5 \mu \mathrm{m}$ large and slenderer spores, and sometimes capitate caulocystidia (Dennis 1970).

Psathyrella pusilla Pegler has only clavate cheilocystidia, no veil and spores that are apically truncate by a germ pore (Pegler 1977). 
Psathyrella subsingeri T. Bau \& J.Q. Yan is a slightly larger species with longer and more slender spores $(\mathrm{Q}=1.4-2.0)$ and differs in ITS sequence (compare Fig. 1; Yan and Bau 2018).

\section{Declarations}

\section{Ethics approval and consent to participate}

Not applicable

\section{Adherence to national and international regulations}

Material Transfer Agreement (MTA) of biological material and documents between the "Institute of Natural Products Chemistry (INPC), Vietnamese Academy of Science and Technology (VAST) Building 1H, Nghia Do - Cau Giay 18, Hoang Quoc Viet, Vietnam" and the "Technische Universität Dresden (TUD), Helmholtzstr. 10, 01069 Dresden, Germany" has been agreed.

\section{Consent for publication}

Not applicable

\section{Availability of data and material}

The raw sequence reads have been submitted to the NCBI Sequence Read Archive (SRA) database under the accession number SRR12301154. The BioProject accession number is PRJNA647680, and the BioSample accession number is SAMN15594885. The fungal strain was deposited at the Vietnam Type Culture Collection (VTCC, Hanoi, Vietnam) under number VTCC 930004. Dried specimen voucher are deposited at the Herbarium Senckenbergianum Görlitz, Germany (GLM-F126263).

\section{Competing interests}

The authors declare that they have no competing interests.

\section{Funding}

This work was financially supported by the Bundesministerium für Bildung und Forschung (BMBF) VnmDiv 031B0627 and CEFOX 031B0831B, further by the Ministry of Science and Technology (MOST, Vietnam) - NDT.45.GER/18. The work has been partly funded by the Fraunhofer Institute for Cell Therapy and Immunology, Branch Bioanalytics and Bioprocesses (PZ-Syn 175-IZI-BB-320250).

\section{Authors' contributions}

Conceptualization: E Büttner, H Kellner

Data curation: E Büttner, A Karich, M Lange 
Formal analysis: E Büttner, A Karich, R Ullrich

Funding acquisition: DH Nghi, M Hofrichter

Investigation: E Büttner, M Lange, A Karich, R Ullrich, H Kellner

Project administration: C Liers

Supervision: H Kellner, C Liers, M Hofrichter

Writing - original draft: E Büttner, A Karich, R Ullrich

Writing - review \& editing: M Hofrichter

\section{Acknowledgements}

We would like to thank Britta Bittner for technical support and Ulrike Schneider for help with lab work.

\section{References}

1. Battistin E, Chiarello O, Vizzini A, Örstadius L, Larsson E (2014) Morphological characterisation and phylogenetic placement of the very rare species Psathyrella sulcatotuberculosa. Sydowia 66 (2) 171181. https://doi.org/10.12905/0380.sydowia66(2)2014-0171

2. Chevreux B, Wetter T, Suhai $S$ (1999) Genome sequence assembly using trace signals and additional sequence information. J Comput Sci Syst Biol 99:45-56

3. Collen B, Whitton F, Dyer EE, Baillie JE, Cumberlidge N, Darwall WR, Pollock C, Richman NI, Soulsby AM, Böhm M (2014) Global patterns of freshwater species diversity, threat and endemism. Glob Ecol Biogeogr 23, 40-51. https://doi.org/10.1111/geb.12096

4. Contu M (1991) Psathyrella bivelata spec. nov., une nouvelle espèce sarde de la section Cystopsathyra. Bull. Trimest. Société Mycol Fr 107, 85-89.

5. de Queiroz JS, Griswold D, Nguyen DT, Hall P (2013) Vietnam Tropical Forest and Biodiversity Assessment, USAID Vietnam.

6. Dennis RWG (1961) Fungi venezuelani: IV. Agaricales. Kew Bull 15, 67-156. https://doi.org/10.2307/4115784

7. Dennis RWG (1970) Fungus flora of Venezuela and adjacent countries. Kew Bull Add Ser 3: 1-531. https://doi.org/10.2307/3758124

8. Edgar RC (2004) MUSCLE: multiple sequence alignment with high accuracy and high throughput. Nucleic Acids Res 32, 1792-1797. https://doi.org/10.1093/nar/gkh340

9. Felsenstein J (1985) Confidence limits on phylogenies: an approach using the bootstrap. Evolution 39, 783-791. https://doi.org/10.2307/2408678 
10. Geyer CJ (1991) Markov chain Monte Carlo maximum likelihood. Computing science and statistics: Proceedings of the 23rd Symposium on the Interface, Fairfax Station Interface Foundation 156-163.

11. Guindon S, Gascuel O (2003) A simple, fast, and accurate algorithm to estimate large phylogenies by maximum likelihood. Syst Biol 52, 696-704. https://doi.org/10.1080/10635150390235520

12. Hoashi Y (2008) Psathyrella turcosomarginata, a new species with cheilocystidia possessing mucoid deposits staining bluish green in ammonia solution. Mycoscience 49, 385-387. https://doi.org/10.1007/s10267-008-0437-1

13. Huelsenbeck JP, Ronquist F (2001) MRBAYES: Bayesian inference of phylogenetic trees. Bioinformatics 17, 754-755. https://doi.org/10.1093/bioinformatics/17.8.754

14. Kearse M, Moir R, Wilson A, Stones-Havas S, Cheung M, Sturrock S, Buxton S, Cooper A, Markowitz S, Duran C (2012) Geneious Basic: an integrated and extendable desktop software platform for the organization and analysis of sequence data. Bioinformatics 28, 1647-1649. https://doi.org/10.1093/bioinformatics/bts199

15. Kimura M (1980) A simple method for estimating evolutionary rates of base substitutions through comparative studies of nucleotide sequences. J Mol Evol 16, 111-120. https://doi.org/10.1007/BF01731581

16. Kumar S, Stecher G, Li M, Knyaz C, Tamura K (2018) MEGA X: molecular evolutionary genetics analysis across computing platforms. Mol Biol Evol 35, 1547-1549. https://doi.org/10.1093/molbev/msy096

17. Ludwig E (2007) Pilzkompendium. Band 2. Fungicon-Verlag Berlin

18. Matheny PB, Curtis JM, Hofstetter V, Aime MC, Moncalvo JM, Ge ZW, Yang ZL, Slot JC, Ammirati JF, Baroni TJ (2006) Major clades of Agaricales: a multilocus phylogenetic overview. Mycologia 98, 982-995. https://doi.org/10.3852/mycologia.98.6.982

19. Melzer A, Kimani VW, Ullrich R (2018) Psathyrella aberdarensis, a new species of Psathyrella (Agaricales) from a Kenyan National Park. Aust J Mycol 27, 23-30.

20. Nagy LG, Kocsubé S, Papp T, Vágvölgyi C (2009) Phylogeny and character evolution of the coprinoid mushroom genus Parasola as inferred from LSU and ITS nrDNA sequence data. Persoonia 22, 28. https://doi.org/10.3767/003158509X422434

21. Nei M, Kumar S (2000) Molecular evolution and phylogenetics. Oxford University Press

22. Örstadius L, Ryberg M, Larsson E (2015) Molecular phylogenetics and taxonomy in Psathyrellaceae (Agaricales) with focus on psathyrelloid species: introduction of three new genera and 18 new species. Mycol Prog 14, 25. https://doi.org/10.1007/s11557-015-1047-x

23. Pegler DN (1977) A preliminary agaric flora of east Africa. Kew Bull Addition Ser 6:1-615

24. Pegler DN (1983) Agaric flora of the lesser antilles. Kew Bull Addition Ser 9:1-668

25. Poynton C (2003) The CIE system of colorimetry. Digit. Video HDTV Algorithms Interfaces 211-231. https://doi.org/10.1016/B978-155860792-7/50087-2 
26. Redhead SA, Vilgalys R, Moncalvo JM, Johnson J, Hopple JS Jr (2001) Coprinus Pers. and the disposition of Coprinus species sensu lato. Taxon 50, 203-241. https://doi.org/10.2307/1224525

27. Ronquist F, Teslenko M, van der Mark P, Ayres DL, Darling A, Höhna S, Larget B, Liu L, Suchard MA, Huelsenbeck JP (2012) MrBayes 3.2: efficient Bayesian phylogenetic inference and model choice across a large model space. Syst Biol 61, 539-542. https://doi.org/10.1093/sysbio/sys029

28. Sammut C, Melzer A (2012) Psathyrellaceae from Malta, a preliminary survey. Veget Medit 27, 3344.

29. Sicoli G, Passalacqua NG, de Giuseppe AB, Palermo AM, Pellegrino G (2019) A new species of Psathyrella (Psathyrellaceae, Agaricales) from Italy. MycoKeys 58, 129. https://doi.org/10.3897/mycokeys.52.31415

30. Singer R (1978) Interesting and new species of basidiomycetes from Ecuador. II. Nova Hedwigia 29 $(1+2) 1-98$

31. Smith AH (1972) The North American species of Psathyrella. Memoirs of the New York Botanical Garden 24: 1-633.

32. Stanke M, Steinkamp R, Waack S, Morgenstern B (2004) AUGUSTUS: a web server for gene finding in eukaryotes. Nucleic Acids Res 32, W309-W312. https://doi.org/10.1093/nar/gkh379

33. van Waveren EK (1985) The Dutch, French and British species of Psathyrella. Persoonia-Suppl 2:1300.

34. Voto P (2011) Psathyrella carinthiaca sp. nov. e nuove segnalazioni di P. bivelata. Riv Micol 2, 121133.

35. Yan JQ, Bau T (2018) The Northeast Chinese species of Psathyrella (Agaricales, Psathyrellaceae). MycoKeys 85. https://doi.org/10.3897/mycokeys.33.24704

\section{Figures}




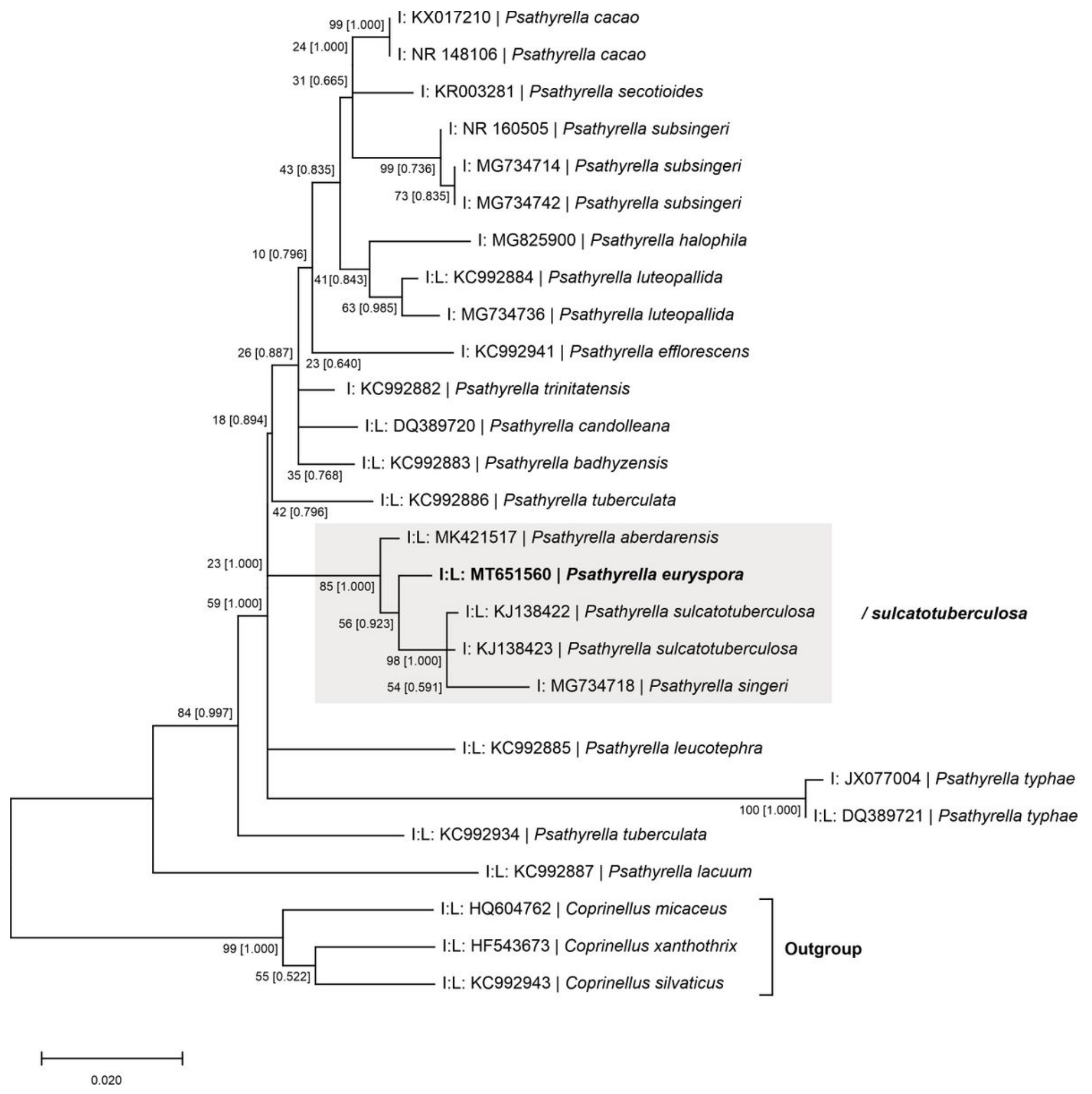

Figure 1

Maximum Likelihood tree inferred from ITS (I) and LSU (L) sequences of P. euryspora (bold) and 26 references estimated using the Maximum Composite Likelihood (MCL) approach (Felsenstein 1985; Kumar et al. 2018) of Psathyrella sect. Candolleanae. Gamma distribution with invariant sites was used to model evolutionary rate differences among sites ( 5 categories; $+G$, parameter $=0.6561$ ) with Kimura $(\mathrm{G}+\mathrm{l})$ 2-paramater model (Kimura 1980). The tree is drawn to scale, with branch lengths measured in the number of substitutions per site. Sampling from the ML tree of the existing molecular data using the 
reconstruction method MCMCMC (Geyer 1991) using MrBayes, values are contained in square brackets. The tree is rooted using Coprinellus spp. as outgroup.

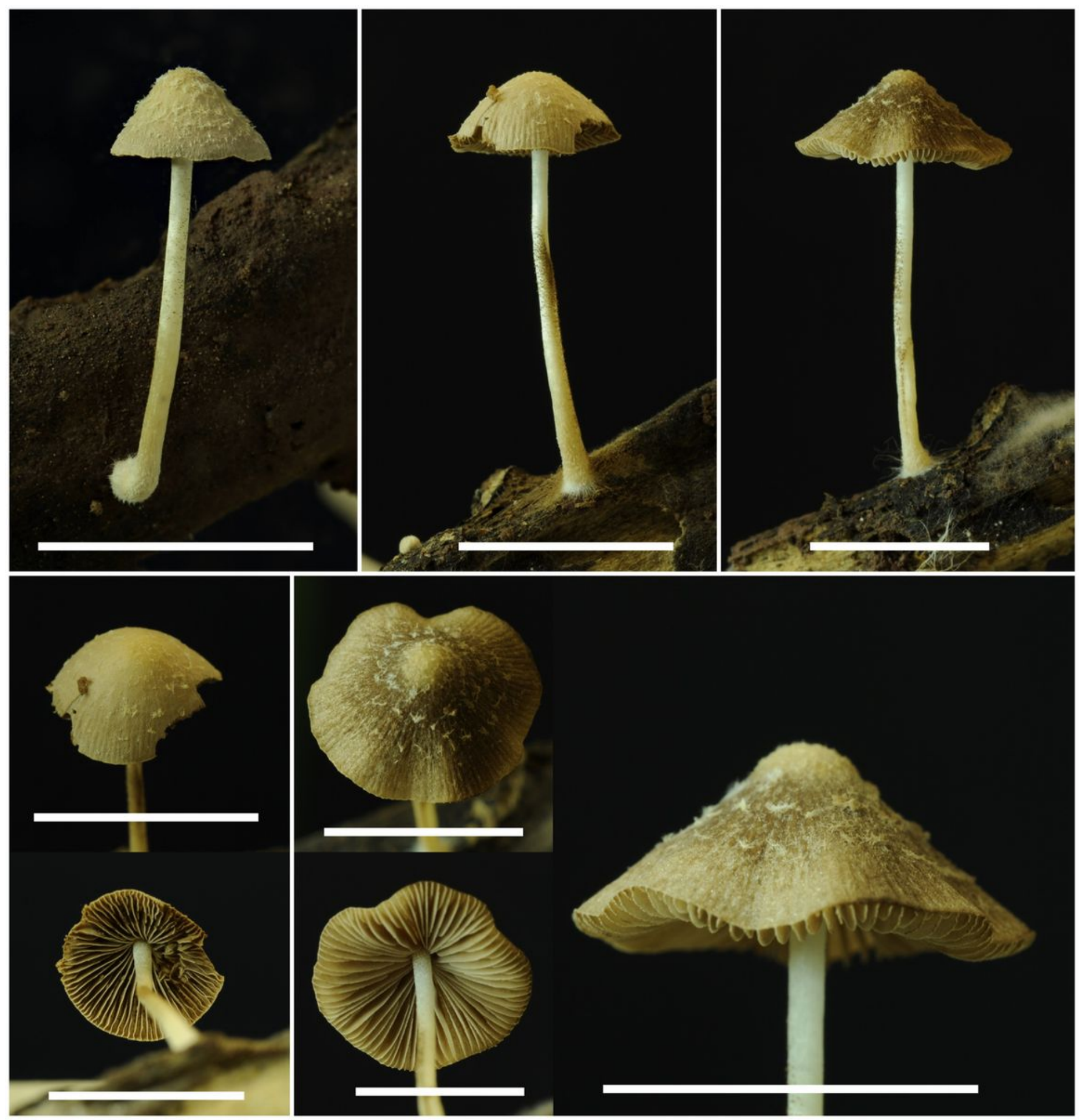

Figure 2

Basidiomata of Psathyrella euryspora. Scale bars: $1 \mathrm{~cm}$. Photographs by Alexander Karich. 

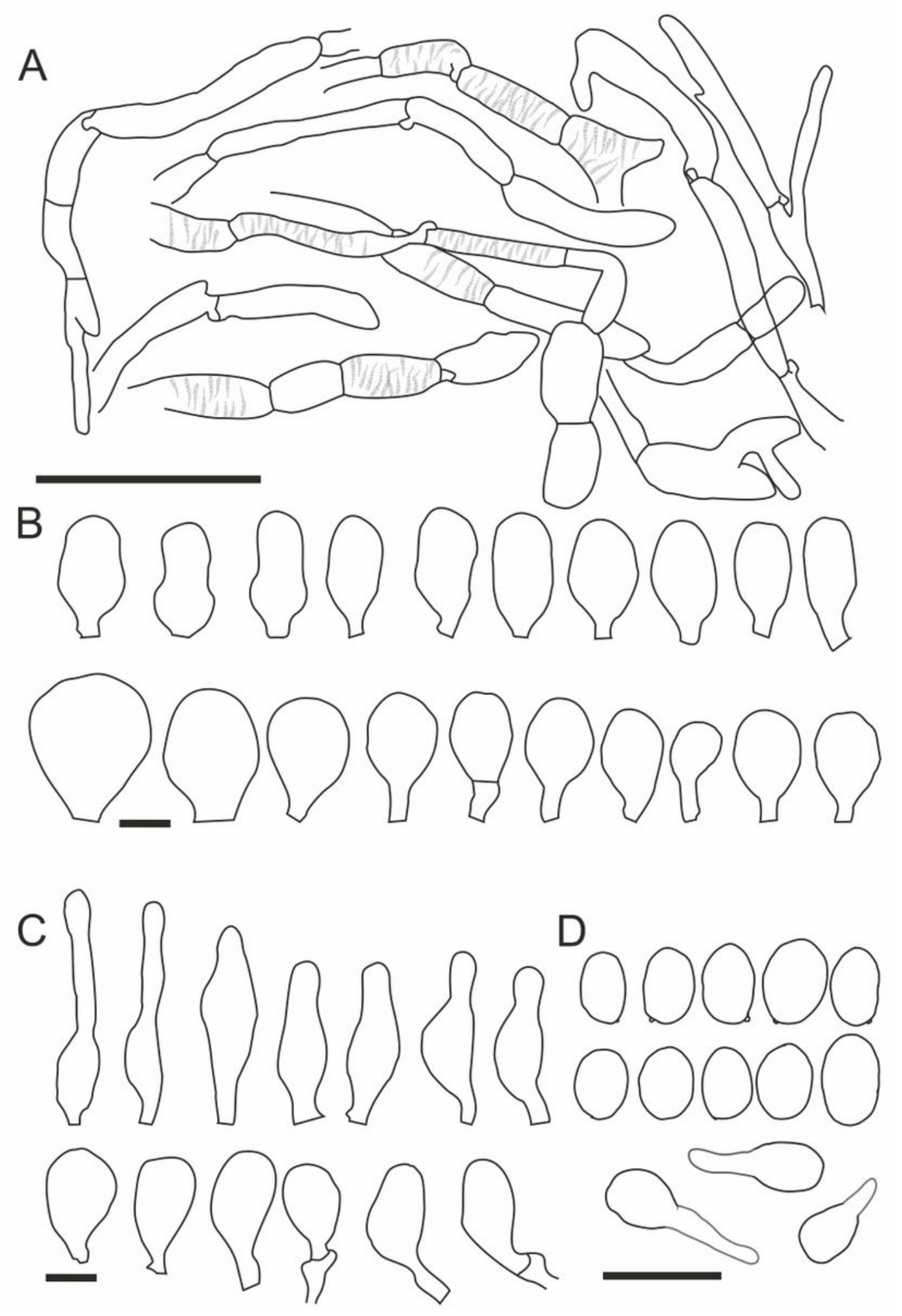

Figure 3

Microcharacters of Psathyrella euryspora; A veil elements, B cheilo- and paracystidia, C caulocystidia, D spores incl. three germinating spores. Scale bars: $50 \mu \mathrm{m}$ (A), $10 \mu \mathrm{m}$ (B-D). Drawing by Alexander Karich. 

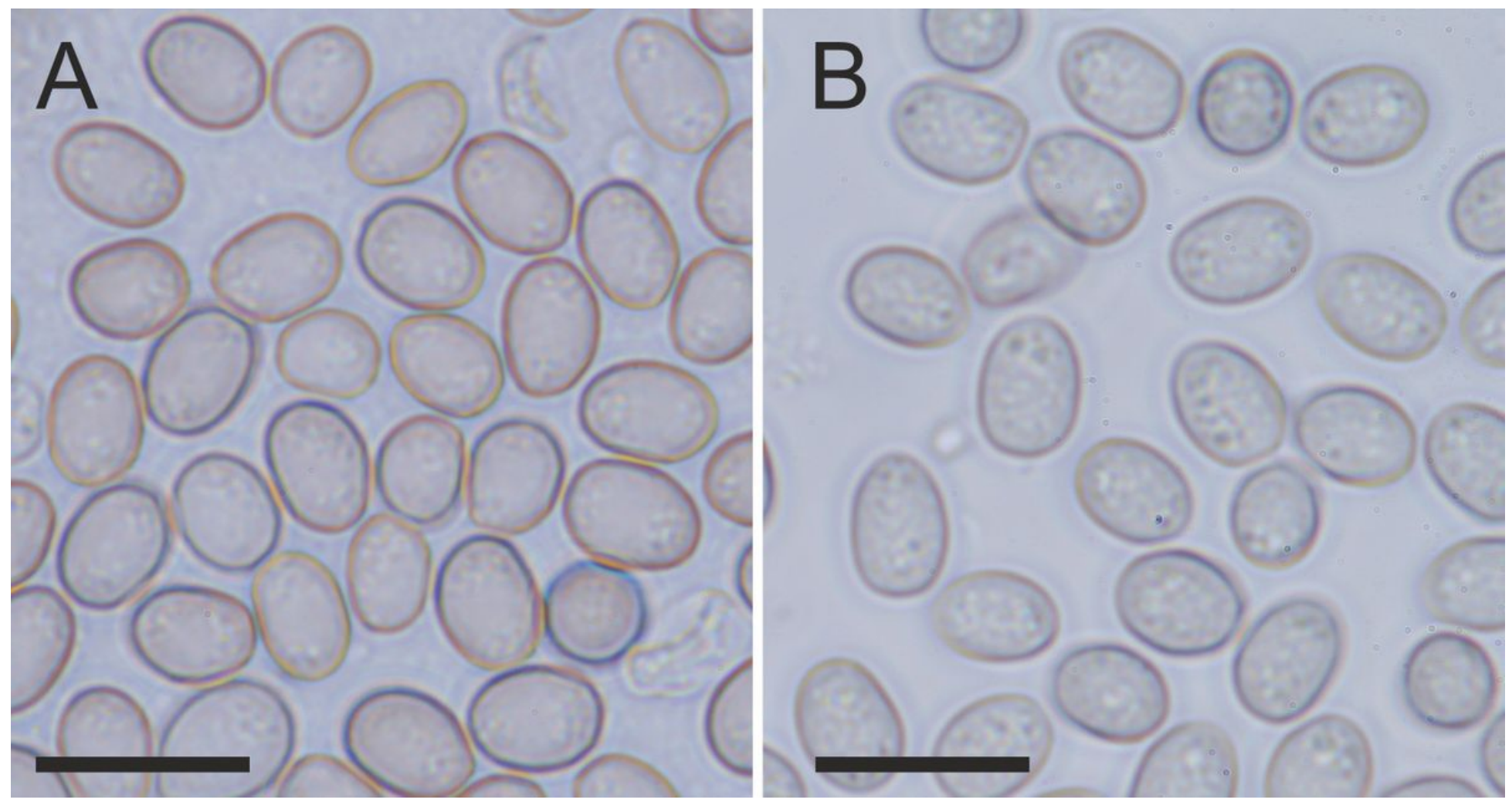

Figure 4

Basidiospores of Psathyrella euryspora in water (A) and in 5\% KOH (B), scale bars: $10 \mu \mathrm{m}$.

\section{Supplementary Files}

This is a list of supplementary files associated with this preprint. Click to download.

- FigureS1.png

- SUPPLEMENTS2.gb

- SUPPLEMENTS1.docx 